EXTENDED REPORT

\title{
Paracetamol in osteoarthritis of the knee
}

\section{Miceli-Richard, M Le Bars, N Schmidely, M Dougados}

Ann Rheum Dis 2004;63:923-930. doi: 10.1136/ard.2003.017236

Background: Paracetamol is a recommended symptomatic treatment of osteoarthritis (OA), but in clinical trials sample sizes have been relatively small and variable daily doses of paracetamol have been used. Objectives: To determine the therapeutic efficacy of paracetamol in OA of the knee and identify predictive factors of clinical response to treatment.

Methods: A double blind, parallel group, placebo controlled trial of analgesic efficacy and safety of paracetamol versus placebo including 779 patients with $\mathrm{OA}$ of the knee. Patients were randomly assigned to receive paracetamol $4 \mathrm{~g} /$ day $(n=405)$ or placebo $(n=374)$ for 6 weeks. Symptomatic OA of the knee was required at inclusion with global pain intensity of the knee during physical activities for the past

See end of article for authors' affiliations .....................

Correspondence to: Professor M Dougados, Cochin Hospital, AP-HP, René Descartes University, Paris, France; maxime. dougados@cch.ap-hopparis.fr

Accepted 24 February 2004 24 hours of $\geqslant 30 \mathrm{~mm}$ on a $100 \mathrm{~mm}$ visual analogue scale. The primary end point was a $30 \%$ decrease of global pain intensity of the knee. Intention to treat analyses were performed.

Results: The percentage of responders did not differ significantly between groups: $52.6 \%$ and $51.9 \%$ in paracetamol and placebo groups, respectively $(p=0.840)$. In a subgroup of patients with chronic mechanical knee pain without signs of inflammation $(n=123)$, the mean change in pain intensity from baseline was $25.2 \mathrm{~mm} \vee 15.2 \mathrm{~mm}$, in the paracetamol $(n=63)$ and placebo $(n=60)$ groups, respectively-mean difference $10.0 \mathrm{~mm} ; 95 \% \mathrm{Cl} 1.0$ to $19.0 ; p=0.0294$. No serious adverse events were attributable to treatment.

Conclusion: A statistically significant symptomatic effect of oral paracetamol $4 \mathrm{~g} /$ day over placebo was not found, suggesting that paracetamol use in symptomatic $O A$ of the knee should be further explored. The tolerability and safety of paracetamol, at the recommended maximum dose of $4 \mathrm{~g} /$ day, was confirmed over 6 weeks.
$\mathrm{P}$ aracetamol, as a symptomatic treatment of osteoarthritis (OA) is recommended as first line treatment by scientific societies: EULAR, ${ }^{12}$ American College of Rheumatology, ${ }^{3}$ North of England, ${ }^{5}$ owing to its good efficacy/safety/cost ratio. These recommendations are based on daily practice and therapeutic trials. Nevertheless, for paracetamol the related controlled trials versus placebo or comparative trials versus non-steroidal anti-inflammatory drugs (NSAIDs) show variable results, probably owing to the low sample sizes and also to the variable daily doses used (2.6-4 g/day). Predictive factors of response are not yet clearly defined for patients with OA and there is some controversy about whether the presence of "inflammation" (flare up) is a predictive factor for analgesic response with NSAIDs. Pure analgesics seem to be more suitable for chronic OA related pain than for an acute phase flare up.

The primary objective of this trial was to determine whether differences in possible therapeutic efficacy might be seen between paracetamol and placebo in outpatients with OA of the knee, in a 6 week, double blind, controlled study. The secondary objective was to assess, after 1 week or 6 weeks of treatment, respectively, the predictive factors of clinical response, and to identify patient profiles in which treatments might be more effective. Safety and tolerability of paracetamol were also assessed in this trial.

\section{PATIENTS AND METHODS}

\section{Patients}

All enrolled patients gave informed written consent before enrolment. Diagnosis of knee OA was made according to the Lequesne criteria. ${ }^{6}$ Symptomatic OA of the knee for at least 3 months was required for inclusion, with a global pain intensity of the knee during physical activities for the past 24 hours of at least $30 \mathrm{~mm}$ on a $100 \mathrm{~mm}$ visual analogue scale (VAS).
Patients were excluded from the study if they had a prosthesis or recent (less than 1 year) surgery of the studied knee; history of allergy to paracetamol; history of hepatitis; severe hepatic or kidney failure; steroids during the past 4 weeks; current treatment with enzymatic inductors or inhibitors; any prior history of asthma or allergy potentially requiring concomitant treatment during the study; pregnancy, lactation, or inefficacious contraception; a history of drug abuse or alcoholism.

The study was approved by the ethics committee of the coordinating site (Hôpital Cochin, Paris, France) and was conducted in accordance with good clinical practice.

\section{Study design}

The study was designed as a double blind, two parallel group, placebo controlled, multicentre trial of 6 weeks' duration, determining the analgesic efficacy of oral paracetamol $\mathrm{l} g$, at a daily dose of $4 \mathrm{~g}$, in patients with knee OA. Patients were included at visit 1 after a washout period of 24-48 hours (see below). Enrolled patients were randomly assigned to paracetamol or placebo groups. Early efficacy and safety data were collected at visit 2 at the end of the first week (day 8). At the end of the sixth week (day 42 or within the 24 hours after the study discontinuation), patients attended the study end visit (visit 3). If a patient had dropped out before the end of the study, the reason was recorded (non-compliance, voluntary withdrawal, adverse drug reaction, treatment failure, etc).

Abbreviations: AEs, adverse events; ITT, intention to treat; NSAIDs, non-steroidal anti-inflammatory drugs; OA, osteoarthritis; VAS, visual analogue scale; WOMAC, Western Ontario and McMaster Universities Osteoarthritis Index 


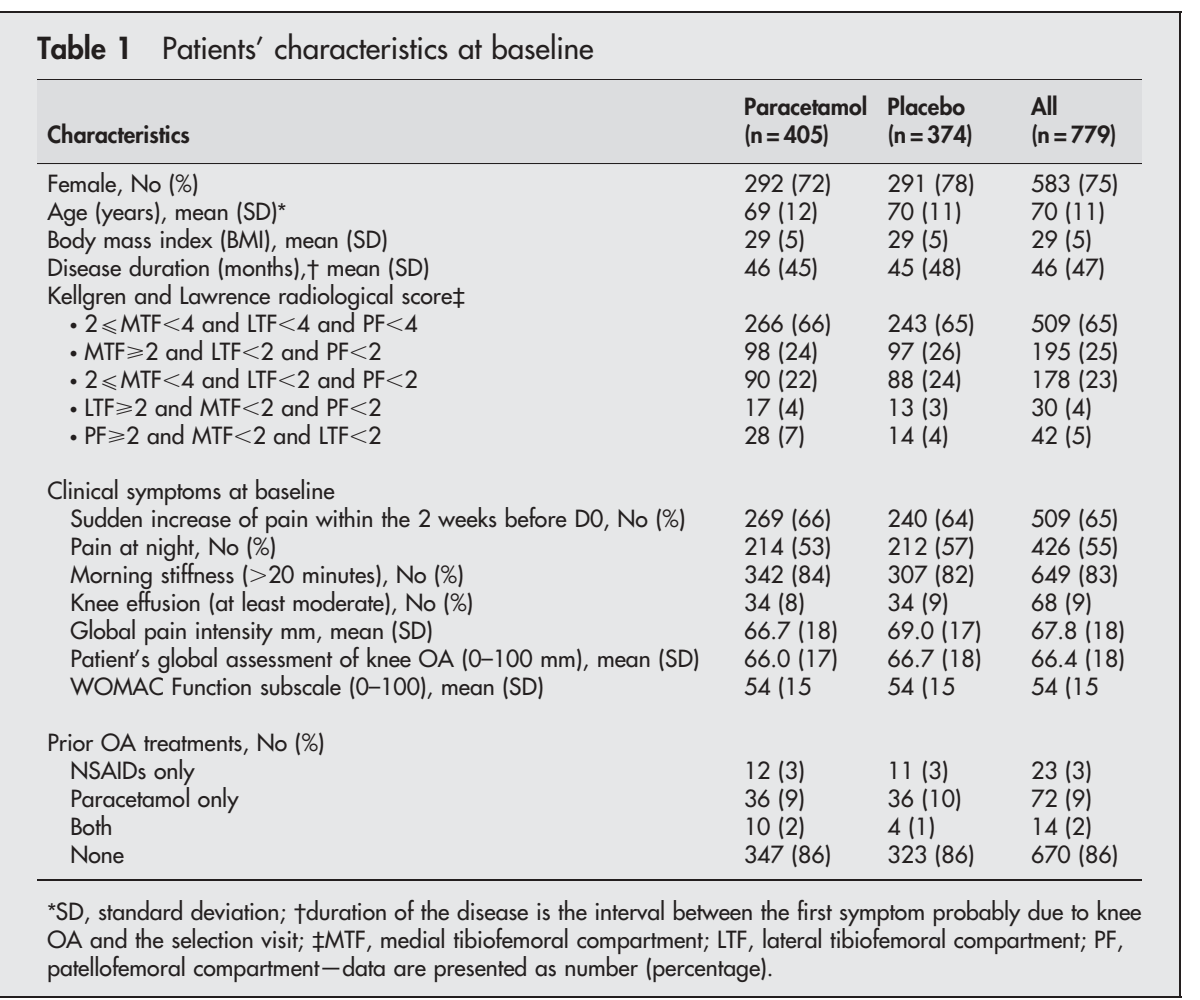

\section{Study drug and concomitant treatments}

The study drug was $1 \mathrm{~g}$ of oral paracetamol or matched placebo, given four times a day, with 4-6 hours between intakes. Patients had to continue treatment for 6 weeks. Compliance was assessed by blister examination and pill count at each study visit. Compliance with treatment was defined as an effective intake of at least $85 \%$ of the theoretical dose (based on the pill count). Patients were washed out of paracetamol or NSAIDs for at least 24 hours (or 48 hours for long half life treatments such as oxicams) before starting the study drug (washout period). Patients who had had an intraarticular injection in the previous 4 weeks were excluded from the study. Concomitant treatments, such as long acting OA drugs, psychotropic or myorelaxing drugs, vitamins or minerals, had to be given at stable doses for at least 3 weeks before inclusion and during the study.

Rescue drugs for OA, such as oral or injectable analgesics (including acetaminophen), NSAIDs, intra-articular drugs, were prohibited during the whole study and patients were interviewed at each visit about their concomitant OA drug treatment.

\section{End points}

Patients were evaluated at week 1 (day 8) and week 6 (day 42 ). The global pain intensity of the studied knee during physical activities for the past 24 hours ( $100 \mathrm{~mm}$ VAS), the patient's global assessment of knee OA for the past 24 hours (100 mm VAS), and the Western Ontario and McMaster Universities Osteoarthritis Index (WOMAC) for physical function (17 item subscale-100 mm VAS) ${ }^{7}$ were assessed. Signs and symptoms suggestive of "inflammation" were also recorded: nocturnal pain interfering with sleep, duration of morning stiffness, joint effusion, and a sudden increase of pain during the previous 2 weeks.

The primary end point was a $30 \%$ decrease of the global pain intensity during physical activities for the past 24 hours.

Secondary end points were responses to treatment, with the minimal decrease in global pain intensity set at $20 \%$ and
50\%; differences in scores from baseline for global pain intensity and patient's global assessment of knee OA severity (absolute and relative values); normalised WOMAC score and OARSI's combined response criteria based on changes from baseline in pain, function, and patient's global assessment of knee $\mathrm{OA}^{8}$ According to OARSI A criteria, a patient was defined as a responder when they had a $45 \%$ decrease of pain intensity and $20 \mathrm{~mm}$ decrease on VAS or two of the three following criteria:

- $15 \%$ decrease of pain intensity and $10 \mathrm{~mm}$ decrease on VAS

- $35 \%$ decrease of OA severity and $10 \mathrm{~mm}$ on VAS

- $30 \%$ decrease of the WOMAC (functional subscore) score and $15 \mathrm{~mm}$ on VAS

According to OARSI B criteria, a patient was defined as responder when they had a $50 \%$ decrease of pain intensity and $20 \mathrm{~mm}$ on VAS or

- $60 \%$ decrease of the WOMAC score and $20 \mathrm{~mm}$ on VAS

or

- $30 \%$ decrease of pain intensity and $15 \mathrm{~mm}$ decrease on VAS.

- $20 \%$ decrease of OA severity and $20 \mathrm{~mm}$ on VAS

- $25 \%$ decrease of the WOMAC score (functional subscore) and $10 \mathrm{~mm}$ on VAS.

\section{Predictive factors of response}

The following patient characteristics were collected at baseline, because they were expected to be predictive factors of response to treatment: demographics (age, weight, height, sex), residence (rural or town dwelling), occupation (sedentary, physical, sporting or other), details of the condition (OA location on the studied knee and involvement of other articular locations), signs and symptoms suggestive of "inflammation" on physical examination. Local or systemic 


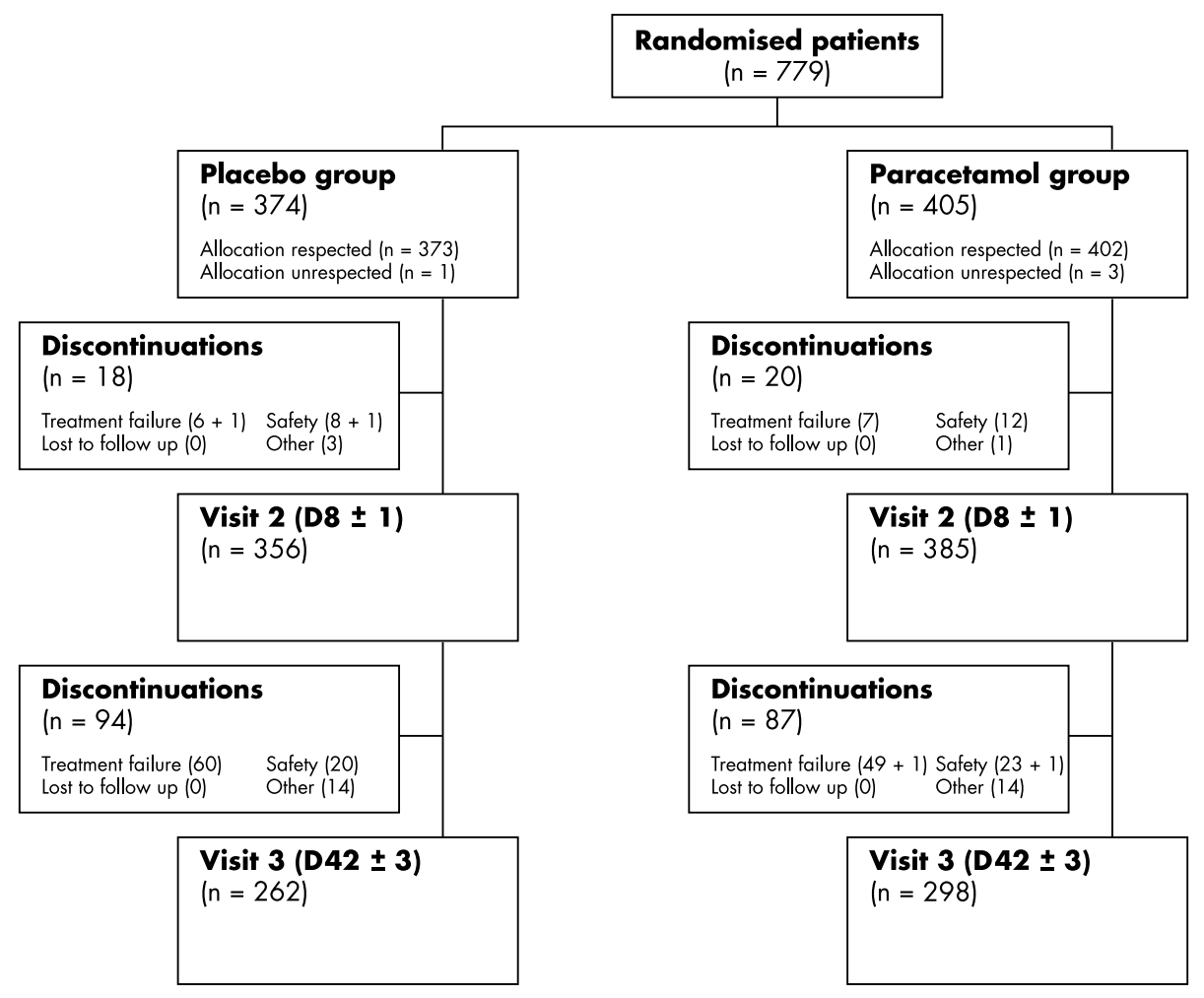

Figure 1 Patients' disposition.

aetiological factors were collected in order to classify OA as primary or secondary, according to the GREES criteria.' Assessment of the radiographic severity of OA was by the Kellgren and Lawrence grading scale. ${ }^{10}$

\section{Sample size determination}

Sample size calculation was based on the primary end point-that is, the percentage of patients responding to treatment after 6 weeks (30\% pain intensity decrease). In the placebo group the estimated percentage of responders was $30-40 \%$; in the paracetamol group the expected percentage was $50-60 \%$. At a two sided $\alpha$ level of $5 \%$, to achieve $80 \%$ power, the minimal required sample size was 387 patients in each group. Initially, it was planned to include 450 patients in each group, allowing for a $10-15 \%$ loss at follow up. Because the loss of follow up was insignificant, the recruitment was stopped when a total of 779 patients had been enrolled. The sample size required for the primary objective was considered adequate to identify potential predictive factors of response to treatment.

\section{Statistical analysis}

Patient disposition and deviations from protocol were studied to determine the analysis populations. Owing to a low rate of major protocol deviations $(3.2 \%$ and $1.9 \%$ in the paracetamol and placebo groups, respectively), only an intention to treat (ITT) analysis was conducted, using the last observation carried forward procedure (including baseline) to manage missing data from patients withdrawn from study (irrespective of reasons).

The percentage of responders $(30 \%$ decrease in pain intensity) and binary secondary criteria were analysed using a $\chi^{2}$ test. Quantitative measures were analysed using analysis of covariance including treatment group as fixed effect and corresponding baseline as covariate.

Predictive factors of response to treatment were identified by various methodologies. Firstly, a logistic regression analysis was conducted to predict the probability of being a responder to treatment. Significance of dependent variables was tested using Wald's test considered at an $\alpha$ level of $10 \%$. Owing to the large number of potential predictive factors, a forward regression method was used to select the dependent variables. This analysis was conducted independently in the two treatment groups to identify factors that were potentially related to a placebo response and by comparison to determine predictive factors that were specific to paracetamol. To explore possible non-linear relationships between predictive factors and response to treatment and to identify cut off points for quantitative baseline characteristics without a priori determination, a decision tree analysis was conducted

Table 2 Changes during the 6 weeks of the study in the three main symptomatic outcome variables by treatment group

\begin{tabular}{|c|c|c|c|c|c|c|}
\hline \multirow[b]{2}{*}{ Outcome variable } & \multicolumn{3}{|c|}{ Changes at week 1} & \multicolumn{3}{|c|}{ Changes at week 6} \\
\hline & $\begin{array}{l}\text { Paracetamol } \\
(n=405)\end{array}$ & $\begin{array}{l}\text { Placebo } \\
(n=374)\end{array}$ & p Values & $\begin{array}{l}\text { Paracetamol } \\
(n=405)\end{array}$ & $\begin{array}{l}\text { Placebo } \\
(n=374)\end{array}$ & p Values \\
\hline Pain VAS $(0-100 \mathrm{~mm})$ & $16(21)$ & $15(21)$ & 0.398 & $23(27)$ & $23(26)$ & 0.660 \\
\hline WOMAC function subscale (0-100) & $8(12)$ & $7(12)$ & 0.499 & 12 (17) & $12(16)$ & 0.580 \\
\hline Patient's global assessment $(0-100 \mathrm{~mm})$ & $14(21)$ & $12(22)$ & 0.063 & $22(26)$ & $20(27)$ & 0.229 \\
\hline
\end{tabular}


Table 3 Predictive factors of response to treatment: results of the logistic regression in the two study groups*

\begin{tabular}{|c|c|c|c|c|c|c|}
\hline \multirow[b]{2}{*}{ Parameter } & \multicolumn{3}{|c|}{ Paracetamol $(n=396)$} & \multicolumn{3}{|c|}{ Placebo $(n=365)$} \\
\hline & Odds ratio & $95 \% \mathrm{Cl} \dagger$ & p Values $\ddagger$ & Odds ratio & $95 \% \mathrm{Cl} \dagger$ & p Values $\ddagger$ \\
\hline $\begin{array}{l}\text { Sudden increase of pain within the } 2 \text { weeks before } \\
\text { inclusion }\end{array}$ & 1.61 & 1.04 to 2.49 & 0.0338 & 1.65 & 1.05 to 2.58 & 0.0297 \\
\hline Morning stiffness ( $>20$ minutes) & 1.64 & 1.05 to 2.54 & 0.0294 & NR & & \\
\hline Pain at night & NR & & & 1.59 & 1.03 to 2.45 & 0.0370 \\
\hline Kellgren and Lawrence radiological score for MTF§ & 0.78 & 0.65 to 0.94 & 0.0081 & NR & & \\
\hline Body mass index (unit $=10 \mathrm{~kg} / \mathrm{cm}^{2}$ ) & 1.68 & 1.10 to 2.56 & 0.0157 & NR & & \\
\hline WOMAC function subscale (unit $=10$ points) & 0.88 & 0.76 to 1.02 & 0.0965 & NR & & \\
\hline Patient's global assessment of knee OA (unit $=10 \mathrm{~mm}$ ) & NR & & & 0.88 & 0.78 to 0.99 & 0.0385 \\
\hline Aetiology (primary or secondary OA) & NR & & & 0.51 & 0.22 to 1.15 & 0.1022 \\
\hline
\end{tabular}

*Response to treatment was defined as a decrease of at least $30 \%$ in pain intensity during the 6 weeks of the study (ITT analysis). Patients included in these analyses are all the patients of the ITT population for whom complete data for the independent variables were available; †95\% Cl, $95 \%$ confidence interval; $¥ W$ ald's test; $\S M T F$, medial tibiofemoral compartment; $\uparrow N R$, not relevant.

separately in the two treatment groups. Patient subgroups that were identified through these two methods were studied to assess the treatment effect on the primary criterion (percentage of responders) using a $\chi^{2}$ test, and the mean changes in pain after 6 weeks using covariance analysis including treatment group (fixed effect) and baseline pain intensity (covariate).

Adverse events (AEs) spontaneously reported by patients or observed by general practitioners were listed, detailing intensity, evolution, and relationship to the study drug. Treatment emergent AEs were coded, before unblinding, using the WHO-ART dictionary, by identifying a preferred term and corresponding system organ. The incidence of treatment emergent AEs was compared between the groups using a $\chi^{2}$ test or Fisher's exact test when appropriate. Analyses were conducted on preferred terms and system organs.

\section{RESULTS}

\section{Patients' baseline characteristics}

Seven hundred and seventy nine patients, aged 18 years or more, were included from November 1999 to August 2000 through 200 French sites by general practitioners. None of the patients were lost of follow up. Overall, 583 (75\%) of the patients were women, with a mean age of 70 years (range 33100) (table 1); more than $70 \%$ of patients had a body mass index equal to or higher than 25; patients were mainly unemployed $(73 \%)$, and living in urban areas (93\%). No significant differences were seen in the demographic characteristics between both groups.

OA characteristics at baseline were also comparable between both groups. OA of the knee was idiopathic in $94 \%$ of cases and associated with another location of the disease in $43 \%$ of cases. Fifteen per cent of patients did not demonstrate any signs of "inflammation" (acute flare up) (see table 1 for details). Overall, mean duration of the disease was 46 months. Pain and patient's global assessment of the disease scores measured at inclusion were higher than $65 \mathrm{~mm}$ and mean functional index (normalised WOMAC score) was 54. Eighty six per cent of patients did not report any analgesic treatment (NSAIDs or paracetamol) at inclusion (table 1).

\section{Compliance}

Seventy two per cent of patients in the paracetamol group and $76 \%$ in the placebo group were compliant over the 6 week treatment period.

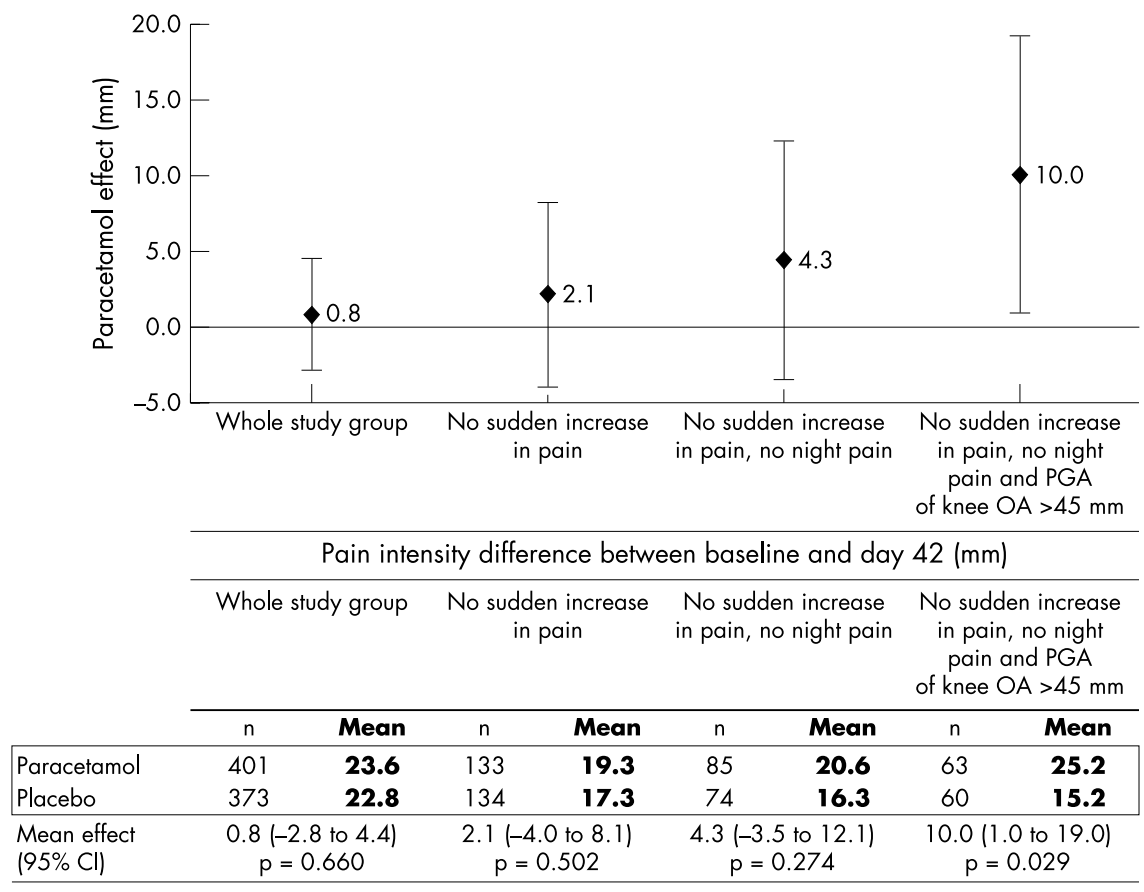

Figure 2 Treatment effect (differences in changes in pain intensity between the two study groups) in different selected subgroups. 


\section{Withdrawals from the study}

Over the 6 week treatment period, a total of 107 (26\%) patients in the paracetamol group and $112(30 \%)$ in the placebo group withdrew from the study. Withdrawals due to treatment failure were noted in $14 \%$ and $18 \%$ in the paracetamol and placebo groups, respectively (fig 1).

\section{Global pain intensity of the knee during physical activities}

For the primary criterion, the percentage of responders $(30 \%$ decrease in global pain intensity) observed in the ITT population $(\mathrm{n}=779)$ was sizeable in both groups $(52.6 \%$ and $51.9 \%$ in paracetamol and placebo groups, respectively) and no significant difference was found $(p=0.840)$. For the percentage of responders when $20 \%$ and $50 \%$ decrease in global pain intensity and other derived criteria were considered, non-significant results were also noted $(61.4 \% \mathrm{v}$ $59.9 \%$ and $36.8 \% \vee 38.0 \%$ in the paracetamol $v$ placebo at week 1 and week 6, respectively) (data not shown).

In absolute values, the mean difference from baseline after 6 weeks was $23 \mathrm{~mm}$ in both the paracetamol and placebo groups (table 2).

\section{Patient's global assessment of knee OA}

Table 2 shows the results for patient's global assessment of knee OA. Mean difference from baseline was $22 \mathrm{~mm}$ for the paracetamol group and $20 \mathrm{~mm}$ for the placebo group. No significant differences were shown between paracetamol and placebo for these criteria.

\section{Normalised WOMAC for physical function}

Table 2 shows the results for the normalised WOMAC OA score at each visit and over the study period (absolute and relative differences from baseline). Mean absolute difference from baseline over the study period was 12 for the paracetamol group and 12 for the placebo group. No significant differences were observed between the groups for any of the criteria derived from the WOMAC OA index for physical function.

\section{OARSI response criteria}

Results for the percentage of responders to treatment as determined by using OARSI's combined response criteria showed no statistical significant differences between paracetamol and placebo groups. The percentage of responders at week 6 were $51 \% v 49 \%$ and $51 \% v 51 \%$ in the paracetamol $v$ placebo groups according to OARSI: criteria A and criteria B, respectively.

\section{Predictive factors of response to treatment}

The first step of this analysis consisted of a logistic regression conducted separately in the two treatments groups to identify factors that were potentially related to a "spontaneous"-type response and by comparison to determine predictive factors that were specific to paracetamol (table 3). In the placebo group, odds ratios suggest that the response to treatment was greater when signs of "inflammation" (that is, a sudden increase of pain within the 2 weeks before inclusion and presence of night pain) were present at inclusion and lower when the disease was more severe (that is patient's global assessment of knee OA). In the paracetamol group, odds ratios suggest that response to treatment was greater when signs of "inflammation" were present at inclusion (that is, a sudden increase of pain within the 2 weeks before inclusion, morning stiffness lasting for more than 20 minutes) and for those with a higher body mass index and lower when the disease was more severe (that is the severity of medial knee OA, defined by the Kellgren and Lawrence score).

As the above analyses showed a relationship between "inflammation" and response, further analyses were conducted.

The decision tree analyses were first conducted separately in the two treatment groups. Several factors were identified as explaining differences in response rates. In the placebo group the response to treatment was greater when signs of inflammation (that is, a sudden increase of pain within the 2 weeks before inclusion, presence of night pain) were present at inclusion and if the disease was less severe (that is, the severity of medial knee OA, defined by Kellgren and Lawrence score $\leqslant 2$ and patient's global assessment of knee

\begin{tabular}{|c|c|c|c|c|}
\hline & $\begin{array}{l}\text { Paracetamol } \\
(n=405)\end{array}$ & $\begin{array}{l}\text { Placebo } \\
(n=374)\end{array}$ & $\begin{array}{l}\text { All } \\
(n=779)\end{array}$ & p Values* \\
\hline Patients with at least 1 TEAE, № (\%) & $85(21)$ & $86(23)$ & $171(22)$ & 0.499 \\
\hline Patients with at least 1 serious $A E$, No (\%) & $5(1)$ & $3(1)$ & $8(1)$ & \\
\hline Patients withdrawn for safety reasons, No (\%) & $36(9)$ & $29(8)$ & $65(8)$ & \\
\hline \multicolumn{5}{|l|}{ Body system involved $\dagger$} \\
\hline Gastrointestinal system disorders, № (\%) & $46(11)$ & $42(11)$ & $88(11)$ & 0.739 \\
\hline Musculoskeletal system disorders, № (\%) & $10(2)$ & $16(4)$ & $26(3)$ & 0.104 \\
\hline Respiratory system disorders, № (\%) & $12(3)$ & $13(3)$ & $25(3)$ & 0.955 \\
\hline Body as a whole-general disorders, No (\%) & $8(2)$ & $12(3)$ & 20 (3) & 0.161 \\
\hline Central and peripheral nervous system disorders, No (\%) & $7(2)$ & $6(2)$ & $13(2)$ & \\
\hline Skin and appendages disorders, № (\%) & $6(1)$ & $4(1)$ & $10(1)$ & \\
\hline Total number of reported AEs & 142 & 132 & 274 & \\
\hline \multicolumn{5}{|l|}{ Intensity $\ddagger$} \\
\hline Mild & $42(30)$ & $30(23)$ & $72(26)$ & \\
\hline Moderate & 77 (54) & $69(52)$ & $146(53)$ & \\
\hline Severe & $18(13)$ & $31(23)$ & $49(18)$ & \\
\hline Missing data & $5(4)$ & $2(2)$ & $7(3)$ & \\
\hline \multicolumn{5}{|l|}{ Relationship with study drugf } \\
\hline Definite & $13(9)$ & $8(6)$ & $21(8)$ & \\
\hline Probable & $38(27)$ & $36(27)$ & 74 (27) & \\
\hline Possible & $28(20)$ & $23(17)$ & 51 (19) & \\
\hline Improbable & 63 (44) & 65 (49) & $128(47)$ & \\
\hline
\end{tabular}


OA score $\leqslant 45 \mathrm{~mm}$ ) (data not shown). Similarly, in the paracetamol group, the response to treatment was greater when at least one sign of inflammation was present at inclusion, and if the disease was less severe (that is, severity of medial knee OA and of the femoropatellar knee OA defined by Kellgren and Lawrence score $\leqslant 2$ and WOMAC $\leqslant 71$ ) (data not shown). These results were very close to those obtained by the multivariate logistic regression models.

Both sets of results suggest that patients presenting signs of "inflammation" or with low severity of OA will probably show an important reduction of pain intensity after treatment, whatever the treatment received. The pain intensity reduction may have been spontaneous, related to the disease "evolution".

Based on these obtained results, we finally performed a decision tree analysis in the subgroup of patients for whom the parameters identified as "spontaneous"-type response (that is, sudden increase in pain, night pain, and patient's global assessment of knee OA $\leqslant 45 \mathrm{~mm}$ ) were absent. Such selection led to 123 "unspontaneous"-type responders. In such a subgroup, the first dependent variable that spontaneously entered the decision tree (that is, which best explained differences in response to treatment) was the treatment group. The calculations showed that $55.6 \%$ of patients were responders to treatment in the paracetamol group $v 38.3 \%$ of responders in the placebo group $\left(\chi^{2}\right.$ test, $\mathrm{p}=0.056)$.

To visualise such results we also calculated the treatment effect (defined as the difference in the changes in pain intensity over 6 weeks between the two study groups, in the differently selected subgroup (fig 2)). In the subgroup of patients with no sudden increase in pain, no night pain, and with patient's global assessment of knee OA $>45 \mathrm{~mm}$ $(\mathrm{n}=123)$, the mean change in pain intensity from baseline was $25.2 \mathrm{~mm} v 15.2 \mathrm{~mm}$ in the paracetamol $(\mathrm{n}=63)$ and placebo $(n=60)$ groups, respectively-that is, a significant paracetamol effect The mean difference between the groups was $10.0 \mathrm{~mm} \quad(95 \%$ confidence interval 1.0 to 19.0 ; $\mathrm{p}=0.0294)$.

\section{Safety results}

The analysis of clinical AEs was conducted on the whole population of patients $(\mathrm{n}=779)$. No significant difference in the incidence of AEs was found between the two groups. Overall, 274 AEs were reported during the trial (142 in the paracetamol group and 132 in the placebo group). Thirty six patients $(9 \%)$ withdrew from the treatment for safety reasons in the paracetamol group and $29(8 \%)$ in the placebo group. These frequencies were comparable between groups ( $1 \%)$. Eight serious AEs were reported (three in the placebo group and five in the paracetamol group). None of them were attributable to the treatment (table 4 ).

\section{DISCUSSION}

This study failed to demonstrate a statistically significant symptomatic effect of oral paracetamol $4 \mathrm{~g}$ /day over placebo in symptomatic OA of the knee, although the percentage of paracetamol responders was as high as expected (52.6\%) before the start of the study. An unusually high percentage of placebo responders was found in patients with OA of the knee $(51.9 \%)$. Nevertheless, complementary analyses suggested that the symptomatic effect might be observed in a subgroup of patients with chronic mechanical knee pain without signs of inflammation (flare up). Moreover, the excellent tolerance and safety profile of paracetamol, even given at the recommended maximum dose of $4 \mathrm{~g} /$ day over a relatively long period of 6 weeks, has been confirmed here.

The failure to demonstrate a symptomatic effect of paracetamol on the whole population of patients evaluated seems in contradiction with some previously published data in clinical trials. The analgesic effect of oral paracetamol has been clearly demonstrated with single (up to $1 \mathrm{~g} /$ intake) or repeated doses (up to $4 \mathrm{~g} /$ day) in acute pain, such as headache, ${ }^{11}$ post partum, ${ }^{12}$ or postoperative pain. ${ }^{13-16}$ Studies evaluating paracetamol in OA are limited, often short lasting, and rarely placebo controlled. Two previous placebo controlled trials (one using a crossover design and the other one a parallel group design), have demonstrated the superiority of oral paracetamol 3-4 g/day. ${ }^{17}{ }^{18}$ Another placebo controlled trial using parallel groups' design, failed to demonstrate any superiority of paracetamol $v$ placebo for treating symptomatic OA of the knee. ${ }^{19}$ However, more recently, Pincus et al in two different placebo controlled trials, using a crossover design, reported a superiority of paracetamol $v$ placebo in pain and WOMAC scores, in patients with symptomatic OA of the knee, but the results were variable and seemed to be period dependent. ${ }^{20}$ Finally, in a recent meta-analysis, Zhang et al clearly demonstrated that paracetamol was effective in relieving pain due to OA (effect size) on pain intensity $v$ placebo was $0.21,95 \%$ CI 0.02 to 0.41$).{ }^{21}$ Note that the effect size on pain intensity of NSAIDs $v$ placebo was $0.34,95 \%$ CI 0.14 to 0.54 .

Based on results of placebo controlled studies ${ }^{17}{ }^{18}$ and also on comparative studies $v$ NSAIDs, ${ }^{22}{ }^{23}$ emphasising the good efficacy/safety ratio of paracetamol, emerging guidelines issued from scientific societies have recommended paracetamol as first line symptomatic treatment of OA. ${ }^{1-424}$

A lack of power of the study does not explain the failure to demonstrate differences between active treatment and placebo, because more than 350 patients in each arm were included to detect a treatment effect of $20 \%$. In line with published data, we have chosen as primary end point a response to treatment defined as an improvement of pain of at least $30 \%$. The percentage of responders in both arms was very high $(52.6 \%$ of responders in the paracetamol group (expected) $\vee 51.9 \%$ in the placebo group (unusual), corresponding to a very small treatment effect $(0.7 \%)$. This observation is similar to that of a systematic review including 29 clinical OA trials using suitable statistical approaches and evaluating the percentage of patients showing at least $50 \%$ of pain relief with different treatments. ${ }^{25}$ The therapeutic effect of paracetamol ( $3 \mathrm{~g} /$ day $)$ with or without codeine $(180 \mathrm{mg} /$ day) but also that of NSAIDs such as ibuprofen ( $1200 \mathrm{mg} /$ day or less) or piroxicam (20 mg/day) was close to that of placebo (around $20-40 \%$ of responders).

The quality of the study does not seem to explain the failure to demonstrate the symptomatic effect of paracetamol because the study was performed according to good clinical practice, with careful monitoring by a clinical research assistant, and an a posteriori control of the data showed that they were concordant with those expected. Thus, demographic data (sex ratio, age, body mass index) as well as symptomatic severity criteria (pain and functional impairment) at baseline were similar to those seen in other studies. ${ }^{26-28}$ Moreover, the level of correlation between data (pain on VAS $v$ functional impairment on a WOMAC scale) corresponded with that reported in previous studies, which were used to elaborate OARSI criteria $^{29}$ (data not shown).

During the study, all rescue analgesics were prohibited and patients were asked at each visit to report the intake of such drugs. However, because this was a community based study (outpatients only), one could not exclude the possibility of self treatment with rescue analgesics, which might have had an impact on the results.

It is usual to differentiate between mechanical pain (occurring after physical activities) and "inflammatory" pain (resting pain interfering with sleep in the second part of the night and associated with morning stiffness). In fact, it has 
been suggested that paracetamol should be proposed for mechanical pain, whereas NSAIDs should be reserved for "inflammatory" flares of the disease. The failure to demonstrate the symptomatic effect of paracetamol in our study may be partly explained by the high proportion of patients with inflammatory pain, because more than $55 \%$ of patients had two or more signs or symptoms suggestive of a flare at the entry visit (data not shown).

Moreover, this study did not exclusively include patients with chronic and mechanical knee pain. Numerous studies define chronic pain as pain lasting for at least 6 months (as defined herein) associated with a daily intake of a symptomatic treatment (NSAIDs or paracetamol) within the month before inclusion. The patients are asked to discontinue the symptomatic treatment at screening. Only patients demonstrating pain increase between screening and enrolment (responders to a symptomatic treatment) are effectively included in the study. ${ }^{27}{ }^{28}$ This method named "flare design" has been usually applied in recently published studies reporting the symptomatic effect of NSAIDs in OA. ${ }^{26}{ }^{30}$ This approach takes advantage of an exclusion of patients with mild OA symptoms, which would probably disappear in few weeks, with or without treatment. The clinical characteristics of the patients enrolled in this study might explain the failure to demonstrate the symptomatic effect of paracetamol. In fact, up to $85 \%$ of the enrolled patients did not receive any symptomatic treatment within the week before inclusion and about $65 \%$ of the patients reported a sudden increase of pain within the 2 weeks before inclusion (table 1). Thus, the marked placebo response seen in our study $(51.9 \%$ of responders at the end of the study in the placebo group $v$ a $30 \%$ expected rate) might be explained by an OA "flare" (justifying a medical visit and the study enrolment) with a spontaneous improvement within the 6 weeks after inclusion. Such an interpretation is supported by the different analyses conducted in order to assess the predictive factors of therapeutic response. In particular, a significant difference $(p=0.0294)$ was found in the mean changes in pain between the two study groups in favour of paracetamol when such analysis was conducted in the subgroup without signs of inflammation (fig 2).

Moreover, this study has confirmed the excellent tolerability and safety profile of paracetamol when given at a daily dose of $4 \mathrm{~g}$ for 6 weeks. There was no increase in AEs related to the study drug as compared with placebo. This is in agreement with the excellent safety record of paracetamol. $^{21} 31-34$

In conclusion, this study conducted in a large number of patients did not confirm the expected symptomatic effect of paracetamol over placebo, at a daily dose of $4 \mathrm{~g}$, on the whole population of outpatients included, suggesting that the use of paracetamol in symptomatic OA of the knee might be further explored. However, complementary analyses suggest that a significant symptomatic effect might be observed in cases of chronic non-inflammatory mechanical knee pain. Further trials are thus necessary to document and confirm this trend.

\section{ACKNOWLEDGEMENTS}

We thank all investigators involved in the study-Philippe Peraudeau for his contribution to the study, Ascopharm for expert data management and study monitoring, and Mr Vasant Manna for critical revision of the manuscript.

\section{Authors' affiliations \\ C Miceli-Richard, M Dougados, Cochin Hospital, AP-HP, René Descartes University, Paris, France \\ M Le Bars, International Medical Organisation/Europe, Bristol-Myers Squibb-UPSA}

N Schmidely, Biostatistics and Data Management Unit, France, BristolMyers Squibb-UPSA

\section{REFERENCES}

1 Pendleton A, Arden N, Dougados M, Doherty M, Bannwarth B, Bijlsma JW, et al. EULAR recommendations for the management of knee osteoarthritis. Report of a task force of the Standing Committee of Clinical trials and Epidemiological Studies. Ann Rheum Dis 2000;59:936-44.

2 Jordan K, Arden N, Doherty M, Bannwarth B, Biilsma JW, Dieppe P, et al. EULAR recommendations 2003: an evidence based approach to the management of knee osteoarthritis. Report of a task force of the Standing Committee for International Clinical Studies Including Therapeutic Trials (ESCISIT) Ann Rheum Dis 2003;62:1145-55.

3 Hochberg MC, Altman RD, Brandt KD, Clark BM, Dieppe PA, Griffin MR, et al. Guidelines for the medical management of osteoarthritis. I. OA of the hip American College of Rheumatology. Arthritis Rheum. 1995;38: 1535-40, II.OA of the knee American College of Rheumatology.Arthritis Rheum, 1995;38:1541-6.

4 ACR. ACR subcommitttee on osteoarthritis guidelines. Recommendations for the medical management of osteoarthritis of the hip and knee. Arthritis Rheum 2000;43:1905-15.

5 Eccles M, Freemantle N, Mason J, for the North of England NSAIDs drug guideline development group. North of England evidence based guideline development project: summary guideline for NSAIDs versus basic analgesic in treating the pain of degenerative arthritis. BMJ 1998;317:526-30.

6 Lequesne M. Arthrose de la hanche et du genou, critères de diagnostic. Indices de mesure de la douleur, de la fonction et du résultat thérapeutique. In: Peyron JG, L'arthrose, problèmes cliniques et fondamentaux actuels, Paris :Ciba-Geigy, 1985.

7 Bellamy N, Buchanan WW, Goldsmith CH, Campbell J, Stitt LWJ. Validation of WOMAC - a health status instrument for measuring clinically important patient relevant outcomes to antirheumatic drug therapy in patients with osteoarthritis of the hip or knee. J Rheumatol 1995;15:1833-40.

8 Dougados M, Le Claire P, Van Der Heijde D, Bloch D, Bellamy N, Altman R. Response criteria for clinical trials on osteoarthritis of the knee and hip: a report of the Osteoarthritis Research Society International Standing Committee for Clinical Trials Response Criteria Initiative. Osteoarthritis Cartilage 2000;8:395-403.

9 GREES: Osteoarthritis section. Recommendations for the registration of drugs used in the treatment of osteoarthritis. Ann Rheum Dis 1996;55:552-7.

10 Kellgren JH, Lawrence JS. Radiologic assessment of osteoarthritis. Ann Rheum Dis 1957; 16:494-501.

11 Steiner TJ, Lange R. Ketoprofen $(25 \mathrm{mg}$ ) in the symptomatic treatment of episodic tension type headache double-blind placebo-controlled comparison with acetaminophen $(1 \mathrm{~g})$. Cephalgia 1998;18:38-43.

12 Skovlund E, Fyllingen G, Landre H, Nesheim BI. Comparison of post-partum pain treatments using a sequential trial design: II. Naproxen versus acetaminophen. Eur J Clin Pharmacol 1991;40:539-42.

13 Seymour RA, Kelly PJ, Hawkesford JE. The efficacy of ketoprofen and acetaminophen (in post-operative pain after third molar surgery. Br J Pharmacol 1996;41:581-5.

14 MacQuay HJ, Poppleton B, Carroll D, Summerfield RJ, Bullingham RE, Moore RA. Ketorolac and acetaminophen for orthopedic postoperative pain. Clin Pharmacol Ther 1986;39:89-93.

15 Skoglund LA, Skjelbred P, Fyllingen G. Analgesic efficacy of acetaminophen $1 \mathrm{~g}$, acetaminophen $2000 \mathrm{mg}$ and the combination of acetaminophen $1 \mathrm{~g}$ and codeine phosphate $60 \mathrm{mg}$ versus placebo in acute postoperative pain. Pharmacotherapy 1991;11:364-9.

16 Schug SA, Sidebotham DA, McGuinnety M, Thomas J, Fox L. Acetaminophen as an adjunct to morphine by patient-controlled analgesia in the management of acute postoperative pain. Anesth Analg 1998;87:368-72.

17 Amadio P, Cummings DM. Evaluation of Acetaminophen in the management of osteoarthritis of the knee. Curr Ther Res 1983;34:59-66.

18 Zoppi M, Peretti G, Boccard E. Placebo-controlled study of the analgesic efficacy of an effervescent formulation of $500 \mathrm{mg}$ acetaminophen in arthritis of the knee or the hip. Eur J Pain 1996;16:42-8.

19 Case JP, Baliunas AJ, Block JA. Lack of efficacy of acetaminophen in treating symptomatic knee osteoarthritis. A randomized, double-blind, placebocontrolled comparison trial with diclofenac sodium. Arch Inernt Med 2003;163:169-78.

20 Pincus T, Koch G, Lei H, Mangal B, Sokka T, Moskowitz R, et al. Patient Preference for Placebo, Acetaminophen (paracetamol) or Celecoxib Efficacy Studies (PACES): two randomised, double blind, placebo controlled, crossover clinical trials in patients with knee or hip osteoarthritis. Ann Rheum Dis 2004:63:931-9.

21 Zhang W, Jones A, Doherty M. Does paracetamol work for osteoarthritis? A meta-analysis of randomised controlled trials [abstract]. Osteoarthritis Cartilage 2003;11(suppl A):S41.

22 Bradley JD, Brandt KD, Katz BP, Kalasinski LA, Ryan SI. Treatment of knee osteoarthritis: relationship of clinical features of joint inflammation to the response to a nonsteroidal anti-inflammatory drug or pure analgesic. $J$ Rheumatol 1992;19:1950-4.

23 Williams HJ, Ward JR, Egger MJ, Neuner R, Brooks RH, Clegg DO, et al. Comparison of naproxen and acetaminophen in a two-year study of treatment of osteoarthritis of the knee. Arthritis Rheum 1993;36:1196-206.

24 American Geriatic Society. Panel on chronic pain in older persons. The management of chronic pain in older persons. J Am Geriatr Soc 1998;46:635-51. 
25 http://www.jr2.ox.ac.uk/bandolier/booth/painpag/Chronrev/OARA/ OANSAID.html (accessed 31 May 2004).

26 Geba GP, Weaver AL, Polis AB, Dixon ME, Schnitzer TJ. Efficacy of rofecoxib, celecoxib, and acetaminophen in osteoarthritis of the knee: a randomized trial. JAMA 2002;287:64-71.

27 Ehrich EW, Schnitzer TJ, Mcllwain H, Levy R, Wolfe F, Weisman M, for the rofecoxib osteoarthritis pilot study group, et al. Effect of specific Cox-2 inhibition in osteoarthritis of the knee: a 6-week double-blind, placebo controlled pilot study of rofecoxib. J Rheumatol 1999;26:2438-47.

28 Bensen WG, Fiechtner JJ, McMillen J, Zhao WW, Yu SS, Woods EM, et al. Treatment of osteoarthritis with celecoxib, a cyclooxygenase-2 inhibitor: a randomized controlled trial. Mayo Clin Proc 1999:74:1095-105.

29 Dougados M, Le Claire P, van der Heijde D, Bloch D, Bellamy N, Altman R. Response criteria for clinical trials on osteoarthritis of knee and hip: a report of the Osteoarthritis research Society International Standing
Committee for clinical trials response criteria initiative. Osteoart Cartilage 2000;8:395-403.

30 Pincus T, Koch GG, Sokka T, Lefkowith J, Wolfe F, Jordan JM, et al. A randomized, double-blind, crossover clinical trial of diclofenac plus misoprostol versus acetaminophen in patients with osteoarthritis of the hip or knee. Arthritis Rheum 2001;44:1587-98.

31 Prescott LF. Therapeutic misadventure with acetaminophen: fact or fiction. Am J Ther 2000;7:99-114.

32 Graham GG, Graham RI, Day RO. Comparative analgesia, cardiovascular and renal effects of celecoxib, rofecoxib and acetaminophen (paracetamol). Curr Pharm Des 2002;8:1063-75.

33 Fored CM, Ejerblad E, Lindblad P, Fryzek JP, Dickman PW, Signorello LB, et al. Acetaminophen, aspirin and chronic renal failure. N Engl J Med 2001;345:1801-8.

34 Singh G. Gastrointestinal complications of prescription and over-the-counter nonsteroidal anti-inflammatory drugs: a view from the ARAMIS database. Am J Ther 2000;7:115-21.

\section{Get published within days of acceptance with} ARD

We are delighted to announce that the Annals of the Rheumatic Diseases launched a "publish ahead of print" programme in February 2004. Selected papers are fast tracked and published online months before they appear in the print journal.

Papers of major significance to the international rheumatology community are published within days of acceptance. The first published article is the raw accepted manuscript; edited and typeset versions are also published as soon as they are available.

In addition to being available on ARD Online, the publish ahead of print articles are searchable through PubMed/ Medline-establishing primacy for your work. They are linked from the ARD Online home page.

$A R D^{\prime}$ s publish ahead of print programme is unique among the major rheumatology journals - to take advantage of this service submit your papers to Annals of the Rheumatic Diseases using our online submission and review system Bench>Press (http://submit-ard. bmijournals.com). For further information contact ARD@bmigroup.com. 